\title{
B2B sales force productivity: applications of revenue management strategies to \\ sales management
}

\author{
Judy A. Siguaw \\ Corresponding Author \\ Cornell University \\ Sheryl E. Kimes \\ Cornell University \\ Jule B. Gassenheimer \\ University of Kentucky
}

\begin{abstract}
Firms should be able to apply the time-based philosophy of revenue management to their sales forces. To do so requires a revision in the way most sales divisions traditionally have viewed salesperson time. Hence, a different type of proposed measure, revenue per available salesperson hour, is proposed to better integrate the value of the salesperson's time as a factor in sales potential and revenue calculation. This article seeks to (1) foster a positive perception of revenue management as a viable sales approach, (2) establish a framework for such a strategy, and (3) set a useful road map for facilitating execution.
\end{abstract}

Keywords: Sales force productivity; Revenue management; Yield management; Sales management; Sales efficiency

\section{Introduction}

Revenue management is the application of information systems and pricing strategies to allocate the right capacity to the right customer at the right place at the right time [1]. Increasingly, revenue management is being adopted across a broad spectrum of industries. For example, not only is revenue management routinely used in airlines and hotels, but it is currently being adopted by restaurants, golf courses, and utility companies, and is being given serious consideration by at least one world-renowned hospital based in the United States [2-6]. The goal of revenue management is to ensure the firm generates the highest possible profits given current customer demand and price sensitivities.

Likewise, sales and marketing managers have similar corporate objectives. Yet, as evidenced by comments of industry representatives attending a recent sales consortium, a major concern of business-to-business (B2B) sales managers is their inability to accurately measure the efficiency and regulate the productivity of their sales force to effectively service diverse customer groups. Despite the numerous measures for governing salesperson performance that have been discussed in the literature for decades [7-11], none have gained sales managers' complete confidence that the bottom-line efficiency and profitability of the sales force is being assessed.

Perhaps other types of measures can better seize the imagination and bolster the assurance of sales managers charged 
with the task of evaluating the performance of the sales force. The most promising developments that capture both dimensions of sales performance and provide guidance on assessing and improving sales performance appear to be innovative applications of revenue management ${ }^{1}$ techniques. There is little evidence that revenue management has been applied to the sales function, but given the revenue management revolution appearing in many industries, the utilization of revenue management strategies for the sales force cannot be far behind. As will be discussed in greater detail later, the sales force represents a perishable specific human asset, which impacts customer relations through the value of services provided [12], and therefore, the efficiency and profitability of day-to-day operations [13]. Given these elements, a revenue management framework can be used to measure sales force efficiency, increase the profitability and productivity of the sales force, and assist firms in better servicing diverse B2B customer groups through integrative transactional and consultative selling models.

Research in revenue management has previously addressed the theoretical and practical operational problems (i.e., pricing and controlling revenue-producing assets) facing airlines, restaurants, and hotels, among other industries [14,15], but has given little consideration to the operational problems confronting the B2B sales forces. The sales function is similar enough to hotel, restaurants, and airline operations in that sales managers should be able to apply revenue-management principles to the services-laden value the sales force provides. By way of example, an occupied hotel room yields customer value by providing a night's rest, an occupied restaurant seat imparts value by securing a meal for the customer, an occupied airline seat results in customer value by providing transportation from one location to another, and occupied salespeople supply customer value through unique problem-solving skills and services. Viewed through the lens of revenue management, then, the firm's sales force represents a revenue-producing asset, operating within the limits of a constrained time frame that imparts value to customers via information, service behaviors, and consultative advice.

A broader conceptualization and application of revenue management that would permit certain businesses with sales forces to increase revenue and profitability without alienating the customer can be adopted. First, revenue management provides an innovative way to measure sales performance, thus, answering the call from industry to develop metrics that measure "marketing performance' in new and creative ways" [16]. Second, revenue management furnishes a baseline for gauging the specific asset value of a salesperson's time. Last, revenue management offers direction to increase the success of the firm by better understanding the costs and benefits the sales force encounters when servicing customers. However, limitations to the use of revenue management also exist. The premise of revenue management applications to the sales force is predicated on a belief that sales representatives do provide cost-laden services and knowledge that are of value to the customer especially in a business environment. If sales managers or customers fail to perceive the value of the sales force, the use of revenue management tactics for assessing sales force productivity is inappropriate.

The objective of this paper is to develop a framework illustrating how revenue management could be used to improve the effectiveness of allocating sales force time in B2B settings. Specifically, the paper serves as a directive to sales managers to consider issues important to customers while ensuring that the sales force routinely targets the most

\footnotetext{
${ }^{1}$ In this study, revenue management is synonymous with another often- used term-yield management.
} 
profitable customers. In this paper, current methods of sales force evaluation are briefly reviewed followed by a discussion of revenue management. The necessary conditions and strategic levers needed for heightening the effectiveness of a revenue management approach, the tactics for utilizing sales revenue management, and potential outcomes of this sales force metric are then discussed. Each of these components is delineated in a framework that unifies the tactical tools for the application of revenue management as applied to the sales force (see Fig. 1). Further, the benefits and, where applicable, the limitations of adopting sales force revenue management strategies are presented. Finally, conclusions and managerial implications are provided.

\section{Overview of methods of B2B sales force evaluation}

Many B2B sales forces are currently governed by various ad hoc revenue management-related practices, but the application has so far been mostly tactical with little direction for an overall strategic framework. Quotas, sales volume, gross margin, calls per day, order-call ratio, and expense ratios are common quantitative methods used to determine whether the sales force is meeting performance standards. Customer satisfaction scores, product knowledge, attitude, selling skills, appearance, initiative, and knowledge of the competition are among the more popular qualitative methods used in evaluating B2B sales performance $[17,18]$.

Moreover, academicians have developed a number of sales models to determine allocation of selling efforts. While the pioneers in this stream of research are to be commended, the models yielded are frequently too complex for general practitioner use. For example, Lodish's [10,19] and Montgomery et al.'s [20] "simple" models require an intri-

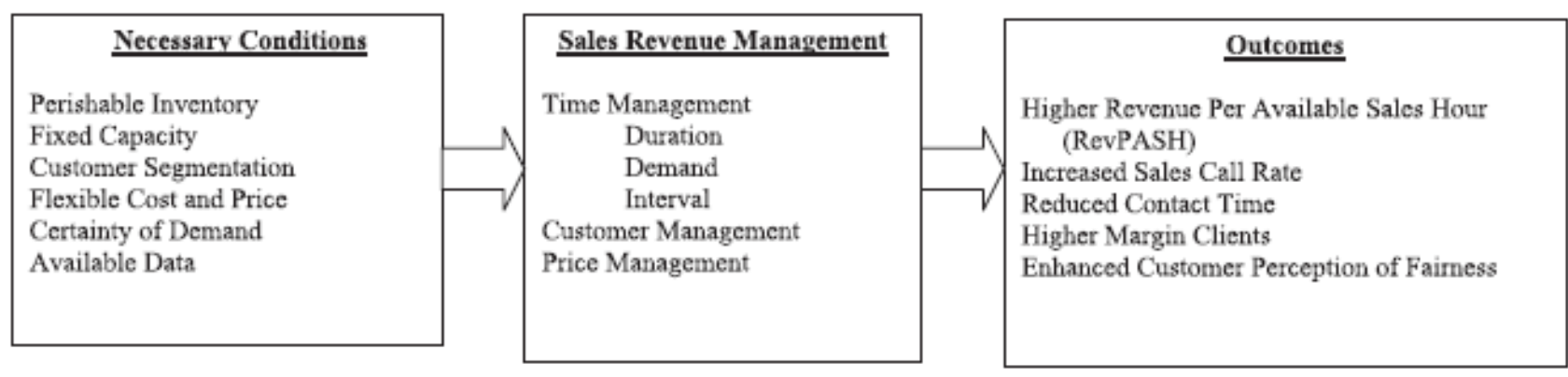

Fig. 1. Framework for sales revenue management.

cate calculus-based programming approach, and they do not take into account the buying preferences of the customer. Other sales models often suffer similar problems [21-25]. Indeed, in their comparison of sales decision models, LaForge and Cravens [26] note:

The empirical approach consists of identifying appropriate predictor and response variables, measuring those variables for a previous period, and then estimating response function parameters using multiple linear regression on the logarithmically transformed variables. ... In contrast, the judgment based SDM approach typically involves having management and/or sales personnel directly estimate the expected future sales response from each planning and control unit to different levels of selling effort. These discrete estimates are transformed into continuous response functions through the use of various curve-fitting procedures. 
Revenue management is a simpler sales decision tool and more relevant to marketing managers. A hybrid of comparative sales analysis, customer cost analysis, and behavior- based assessment, the technique takes a managerial perspective and brings relevance and realism into the firm. It combines information in relation to customer segmentation, pricing, products, and promotion. By identifying what is important to customers, segmenting the customer market strategically, and focusing on the selling function, in conjunction with other components of the marketing mix, management can better control costs and obtain profits $[27,28]$. Revenue management also provides a basis for comparison of efficiency and effectiveness across the members of the sales force, as well as facilitating sales allocation efforts.

\section{Background of revenue management}

Revenue management consists of techniques that allow managers to gain more insight into customers buying behaviors and consequently, to make adjustments in the marketing mix to maximize revenue and achieve significant increases in profitability through customer preferences. Traditionally, revenue management has meant using demandbased pricing so that price-sensitive customers who are willing to purchase at off-peak times can do so at favorable prices, while price-insensitive customers who wish to purchase at peak times may also do so, but at higher prices.

Revenue management surfaced in the airline industry in the late 1970s as the industry struggled with increased competition due to deregulation [29,30]. Revenue management strategies have since been adopted by the hotel, restaurant, and golf industries $[3,4]$ and potential applications are being examined within the healthcare industry. The electrical utilities industry has also found revenue management useful in regulating electricity usage during peak and offpeak times [6].

The ability to effectively implement revenue management strategies in different industries is subject to the various combinations of duration control and variable pricing that exist within each commercial sector [30]. Table 1 (adapted from Ref. [30]) illustrates the various combinations of price and duration and specifies the type of industries that correspond to each combination. The most effective applications of revenue management are generally found in industries in which both duration and price can be managed (see Quadrant 2). Consequently, it is not surprising that industries traditionally associated with revenue management (i.e., hotels, airlines, car-rental firms, and cruise lines) are those that are able to apply variable pricing for a product or service that has a specified or predictable duration. On the other hand, some businesses (e.g., movie theaters, performing-arts centers, arenas, and convention centers) charge a fixed price for a product of predictable duration (Quadrant 1), while still others (e.g., restaurants and most Internet service providers) charge the same price for all customers purchasing a particular product or service, but face a relatively unpredictable duration of customer use (Quadrant 3). Finally, a few industries, such as health care, charge variable prices (e.g., Medicare vs. private pay), but do not know the duration of customer use, although some may try to control that duration (Quadrant 4). The lines dividing the quadrants are broken because in reality no fixed demarcation point exists between quadrants; thus, an industry may have attributes from more than one quadrant.

While revenue management has typically been applied to consumer service industries, it can also be applied to B2B 
services and to manufacturing. As long as the industry possesses the characteristics necessary for revenue management (described in detail below), revenue management is a feasible business approach.

Revenue management applications in broadcasting and energy services have recently surfaced (see Table 2) [31,32]. Both industries sell time (broadcasting sells 30 - second slots and energy services sell months of natural gas usage) for a

Table 1

Typical pricing and duration positioning of selected service industries

\begin{tabular}{lll}
\hline Duration & Pricing & \\
\cline { 2 - 3 } & Fixed & Variable \\
\hline Controlled & Quadrant 1 & Quadrant 2 \\
& Movies & Hotels \\
& Stadiums/arenas & Airlines \\
& Convention centers & Rental cars \\
& & Cruise lines \\
Uncontrolled & Quadrant 3 & Quadrant 4 \\
& Restaurants & Continuing care \\
& Golf courses & Hospitals \\
\hline
\end{tabular}

Adapted from Kimes and Chase [30].

variety of prices. Conversely, some industries, such as the data services industry, sell a fixed amount of time/space for a set price, while others, such as environmental and janitorial services offer services of unknown duration for a set price. Finally, other industries, such as communication services, electronic document management, and commercial real estate sell services in indeterminate length at variable prices.

The appropriate revenue management strategies vary by quadrant. For example, industries occupying Quadrant 2 need to refine their prediction of duration and control of pricing to achieve increased revenues. Industries occupying Quadrant 1 , with their relatively controlled duration, must focus on the application of demand-based pricing, while industries in Quadrant 3 have two levers (both duration control- and demand-based pricing) at their disposal. Finally, industries residing in Quadrant 4 must concentrate on increasing their control over duration.

The same schema can be used to position specific revenue-generating assets of a firm (see Table 3). For example, an electronic document management firm has a number of different functions that can be segmented into the pricingduration matrix. For example, storage and retrieval, microfilm scanning, and digital engineering are in Quadrant 1 (controlled duration and fixed pricing), while file conversion with special scripting) is in Quadrant 2 (controlled duration and demand-based pricing). Engineering and large format services and sales operations fall into Quadrant 3 (uncontrolled duration and fixed pricing), and data entry and litigation support fall into Quadrant 4 (uncontrolled duration and demandbased pricing) [33].

To improve revenue streams, the firm should shift non-Quadrant 2 operations involving specific revenue-generating assets to Quadrant 2. For example, storage and retrieval (a Quadrant 1 business function) could focus on deploying better demand-based pricing, while data entry (a Quadrant 4 business function) could concentrate on better predicting and 
controlling customer duration. Similarly, the sales division (a traditionally Quadrant 3 business function) could alter its operations by predicting the amount of time that will be invested in each customer and using demand-based pricing. In turn, these practices, with minimal decline in customer satisfaction, should produce greater sales efficiencies and

Table 2

Typical pricing and duration positioning of $\mathrm{B} 2 \mathrm{~B}$ industries

\begin{tabular}{lll}
\hline Duration & Pricing & \\
\cline { 2 - 3 } & Fixed & Variable \\
\hline Controlled & Quadrant 1 & Quadrant 2 \\
& Data services & Broadcasting \\
& Corporate meeting services & Energy services \\
& & Freight services \\
Uncontrolled & Quadrant 3 & Quadrant 4 \\
& Environmental services & Commercial real estate \\
& Janitorial services & Communication services \\
\hline
\end{tabular}

Adapted from Kimes and Chase [30].

Table 3

Strategic levers: electronic document management application

\begin{tabular}{lll}
\hline Duration & Pricing & \\
\cline { 2 - 3 } & Fixed & Variable \\
\hline Controlled & Quadrant 1 & Quadrant 2 \\
& Storage and retrieval & File conversion with \\
& Microfilm scanning & special scripting \\
& Digital engineering & \\
Uncontrolled & Quadrant 3 & Quadrant 4 \\
& Engineering and large & Data entry \\
& format services & Litigation support \\
\hline
\end{tabular}

profitability, not only for sales forces within the electronic document management industry, but for sales forces in general. In this study, a revenue management for a B2B sales framework was developed (see Fig. 1). This is composed of three major components: (1) necessary conditions of revenue management, (2) strategic sales force revenue management levers, and (3) outcomes of sales force revenue management. This framework and the discussion that follows, especially surrounding the strategic levers, are intended to serve as a road map to successful implementation of revenue management strategies for the sales force.

\section{Conditions for effective revenue management}

Revenue management has been most effective when applied to operations that have the following characteristics: perishable inventory, relatively fixed capacity, segmented customer markets, flexible cost and pricing structure, certainty of demand, and readily available key data $[14,34,35]$. These attributes are generally present in the sales profession and integral to the proposed strategic framework.

\subsection{Perishable inventory}

One might think of a sales department's perishable inventory as its samples and computers, but in reality, time represents inventory specific to the salesperson-or, in this case, the time during which a salesperson is available to 
convey useful knowledge to customers. A salesperson's time perishes throughout the day along with the ability to offer timely, human-specific services to the customer. If a salesperson is not occupied in revenue-producing activities for a period, that part of the salesperson's inventory perishes and specific skills and knowledge are wasted.

The perishability of a salesperson time is the key to the proposed strategic framework and represents the element that has been missing in previous approaches to B2B salesperson management. Consequently, instead of measuring sales volume or revenue for a given day or month, sales managers should measure revenue (or profit) per available salesperson hour (RevPASH). Simply stated, RevPASH is calculated as revenue (or profit) generated for a specific period (e.g., day, month) by the number of sales hours available during that interval. RevPASH should better capture the time factor involved in obtaining sales and provide an improved assessment of the value a salesperson's contact time and call potential generates in a day.

\subsection{Relatively fixed capacity}

Sales force capacity generally remains fixed over the short term. While sales managers can add a salesperson, adjusting the size of the sales force represents a significant asset investment in terms of hiring and training costs. Furthermore, a salesperson's time capacity remains relatively constant over the long term as an individual establishes the number of hours he/she is willing to work under normal circumstances. Given this stability, sales force capacity may be best measured using the number of hours a salesperson normally works. While most sales managers' approaches to optimizing revenue primarily involve fulfilling sales quotas, that effort may be less effective in generating revenue than basing expectations on the efficient use of salesperson time. A volume quota may encourage the sales force to heavily discount prices to surrender to the opportunistic demands of customers, thereby, reducing company profitability. Or making quota early might encourage a salesperson to take a lackadaisical approach to his/her remaining sales hours. Employing "salesperson hours available" to capture sales capacity overcomes the aforementioned problems and encourages the salesperson to charge according to "opportunity costs" and thus, perceived worth.

\subsection{Customer segmentation}

Another important characteristic inherent in effective revenue management is the ability to segment customers into those sensitive to price and those sensitive to time. Customer segmentation calls for strategic approaches that use customer value to maximize sales and cover costs while remaining competitive $[28,36]$. Revenue management is an aggressive micromarket approach to maximizing sales with an eye toward customer and market orientations that firms can use to segment customers into groups based on the elasticity of "perceived value" [37] and use market knowledge to create perceptions of fairness [38]. For instance, the electronic document management industry found that customer preference for off-peak pricing encouraged sales prospects to accelerate their document imaging plans, thereby filling previously unused production capacity and increasing marginal revenue, profits, and customer satisfaction through the production function of the electronic document management firm [33].

Revenue management, rather than running counter to customer orientation, means that customers have the option to get the service they want, when they want it, and to accept the cost trade-off consequence [34]. For example, some 
customer segments want to utilize the knowledge and consultative skills offered by a salesperson during peak-demand times and expect a high level of service. Based on revenue management principles, these customers should be willing to pay a higher price based on the perceived value obtained from the services rendered. Other customers consider their purchases purely transactional in nature and prefer to receive discounted prices. Because this segment places greater value on financial savings, these customers should be willing to shift to off-peak times and to forego certain salesperson service components as a means of obtaining lower prices $[28,39]$.

Viewing the sales force as a revenue generator and a value creator underscores the customer-value system and provides justification for charging higher prices through personal interaction that requires peak or substantial contact time. By effectively planning, scheduling, and pricing sales force time based on the characteristics and needs of each customer segment, firms can more effectively utilize the sales force and enhance sales force revenue and long-term profitability without jeopardizing customer profitability and commitment.

\subsection{Flexible cost and price structure}

Sales force salaries, benefits, and technological equipment are relatively fixed expenses for the firm and wasted sales force time does little to recover these fixed costs. Conversely, commissions, communication, travel, and entertainment expenses vary and can be regulated to reflect incremental changes in sales revenue. The pricing structure of the firm's proffered product/service must generate sufficient revenue to offset fixed costs and cover variable costs of the sales operation. The concepts of "full fare" from the airline industry and "rack rate" in the hotel industry help establish the customer reference price and have equal applicability to sales. Although a few industries, such as pharmaceuticals, may not allow their sales forces any flexibility in pricing, whenever possible, management should encourage flexible goods pricing to reflect the elasticity of demand by reducing prices during periods of low demand (which reduces commissions but covers the salary structure) and charging the full price during periods of high demand (which increases commission while also covering the salary structure). A common revenue management practice is to have a range of prices in which the revenue management system recommends a minimum acceptable price.

\subsection{Certainty of demand}

Demand uncertainty restricts the sales manager's ability to make efficient sales force time-allocation decisions. With sales force time and a limited and perishable asset, revenue management requires salespeople to expand information boundaries to better predict and segment customers' time demands. For example, technology designed to track patterns of appointments-including waiting time, travel time, planned appointment duration, and unexpected appointment cancellation-would provide a baseline for better determining the specific time investment per appointment regardless of a sales outcome. Understanding where time is invested and the revenue generated from these incremental times establishes a baseline for meeting performance expectations and a level of time tolerance needed to effectively close the sale.

While the ability to generate the information needed to increase certainty of demand may be more difficult for those firms that sell to industries with very long buying cycles, efforts to reduce demand uncertainty will still assist managers. 
Besides, even in long-term sales situations, sales representatives are already able to predict an average sales cycle and usually have an idea of how many sales calls are required. For example, the division of ARAMARK that provides food and laundry services to city, county, and federal prisons recognizes that an average sales cycle is 2 years because of all the different levels of bureaucracy involved in the purchase decision [40]. Thus, increasing information about appointments even over the long-term may not be prohibitive to effectively estimate and implement a revenue management system.

\subsection{Available data}

At a minimum, revenue management systems require data concerning supply, demand, market segmentation, length of usage, cost and price, and no-shows. For a sales force revenue management system, this translates into the need to have detailed information that tracks a salesperson investment in time relative to demand per customer segment, sales revenue, and no-shows/cancellations by time of year, day of week, and time of day. Fortunately, technology has enabled companies to easily record and analyze these data (cf. Refs. $[41,42]$ ). Many firms in the electronic image management industry, for example, use an application service provider (ASP) solution to track their sales force's sales goals vs. goals attained, organizational level of prospective sales contacts, time and date of each sales call, number of sales calls scheduled per day, success rates within vertical markets (e.g., healthcare), and market segments of each sales, as well as a range of other critical information [33]. Further, this data collection and analysis is no more extensive than examining data needed to conduct current recommended methods of sales force evaluations and to assist with sales forecasting $[33,43]$.

\section{Sales force revenue management levers}

A profitable revenue management strategy is predicated on effective control of customer demand and a flexible pricing strategy. Following the guidance of Kimes and Chase [30], three strategic levers are offered for managing and reducing the uncertainty of demand and revenue commonly associated with the sales function: time management, price management, and customer management.

\subsection{Time management}

Three methods for governing sales force appointment time exist: (1) reducing the uncertainty of contact duration, (2) reducing the uncertainty of demand, and (3) reducing the contact interval.

\subsubsection{Uncertainty of duration}

Conventional wisdom suggests that customers' use of sales force time implies an unlimited right of passage rather than an appendage of the purchased product or service. However, sales force time is valuable and can be expensive to the firm if it is not properly utilized. Therefore, the prices of the firm's offerings must cover the cost of the sales force's services, as well as overhead expenses. If sales force time is not efficiently used, the firm may suffer reduced profit margins or incur losses with every sales call made. To counter this problem, sales managers can focus on improving revenue by coordinating contact time and pricing. To begin, sales managers could retrieve or collect data tracking the length of contact by sales objective, customer characteristics, time of year, day of week, and time of day; indeed, as previously noted, some 
companies are already collecting these data through the use of ASP technology [33]. Identifying areas for duration discrepancy provides a basis for forecasting variation and understanding reasons for and correcting inconsistencies.

\subsubsection{Uncertainty of demand}

Planning reduces uncertainty and establishes a roadmap for guiding day-to-day operations. However, even plans can go astray. Hotels, restaurants, and airlines frequently encounter unexpected no-shows. Similarly, in B2B sales, representatives often find clients have been unexpectedly delayed or are completely unavailable. Hotels, restaurants, and airlines generally use two methods-confirmations and incentives-to reduce uncertainty of demand. Sales representatives could use similar techniques to salvage potential dead time and reduce the uncertainty of being forced to waste valuable contact time.

Sales representatives should plan to confirm appointments several days prior to the scheduled time to avoid shortterm cancellations that leave a salesperson doing nonrevenue-producing activities (e.g., paperwork) to fill this "prime" nonscheduled "dead" time. The inefficient use of prime selling time lowers revenues for the company and potentially lowers income levels for the salesperson. Should sales representatives continue to experience noshows or short-term cancellations, the sales manager might advise the sales force to prospect to generate additional contacts and potential revenue. Prospecting is a means of qualifying potential customers before making appointments [44]. As with customer contacts, prospecting requires the use of "prime" selling time. Effective prospecting balances the cost of unused salesperson contact time with the revenue generated in the future from new customers.

Another method to reduce the uncertainty of unproductive time is to sporadically offer incentives, such as discounts or credit, to customers to fill unexpected down time. Some B2B companies use discounts, for example, during their slow season to entice customers to generate business [33]. This approach serves to increase sales force productivity by providing them with a valid reason to gain entry and to move reticent prospects to a close. At the same time, these discounts help the organization fill a void within the production facility, so that capacity does not go unused; thereby increasing marginal revenues. Other firms may use an incentive to encourage customers to do business. For example, one oil- well control and intervention firm offers a "free" well plan review and critique as a "hook" to generate additional business regarding blowout contingency plans [45]. Airlines and cruise ships employ spur-of-the-moment supersavers to increase occupancy rates, if only to help cover fixed cost. Restaurants offer free drinks or desserts to stimulate demand. While sales divisions have been slow to adopt incentives for existing customers, the sales force could use discounts, credit, and specials, specifically designated to be employed during nonscheduled dead time or through alternative selling channels (via telephone, Internet) that would be valued by the prospective customer. In the case of prospects, long-term revenues may result once the prospect is enticed to try the product and is satisfied with the results.

\subsubsection{Reducing appointment interval}

The sales profession has routinely been viewed as a "numbers game;" the greater the number of qualified prospects directly contacted, the greater the number of sales closed and revenues generated [46]. Hence, reducing the time between appointments should increase capacity and potential revenue. A similar strategy has been utilized by airlines in their 
efforts to decrease changeover time. For example, Southwest Airlines and the Shuttle by United both boast 20-minute aircraft turnarounds and have thereby been able to increase plane use [5]. Likewise, by determining the appropriate contact length for each customer segment and scheduling appointments with companies located in immediate proximity, sales managers may find that sales appointments can be scheduled closer together, increasing the number of appointments each working day. By way of an elementary example, an additional sale a week would result in 52 incremental sales per year per salesperson. This in conjunction with the knowledge of how often customers make purchases provide guidelines for pacing customer contact and using time effectively [41,42].

\subsection{Price management}

Similar to the technique of using discounts to stimulate demand for the sales person, demand-based pricing can be used to help increase RevPASH. For example, during seasonal periods when the supply of salesperson time exceeds demand, managers could offer discounts or credit to cover the fixed cost of underutilized time. This approach is also useful when the number of sales directly impacts the ability to better utilize the capacity of the production function. As long as prices cover the incremental or variable cost of the salesperson's time and do not destroy the perceived value of a service, nor cannibalize markets intended to pay full prices, the strategy of choice might well be price, thus, making price fences important. Price fences are rules used to rationally bound customers to specific market segments and reduce uncertainty in demand over time.

\subsubsection{Price (rate) fences}

Prices can be customized by developing various rules (i.e., price fences) to limit the price to particular market segments $[2,47]$. Hotels and airlines use price (i.e., rate) fences to offer discounts on inventory that might otherwise not be sold at all to customers who might otherwise not purchase-while at the same time preventing customers who were going to buy anyway from taking advantage of a discount that they did not actively seek [2]. Thus, coach passengers flying from Chicago to Los Angeles may pay nothing (for those using frequent flyer vouchers) or over US\$1500 for the same seat. The fares vary according to the time of the reservation, the days that the individual is flying, and group or company affiliations that the flyer might have. The fences can comprise numerous rules and be an effective means of satisfying customers as long as they appear rational and fair to the customer.

Although many options for building price fences exist [47], the emphasis of salesperson revenue management should focus on developing rate fences based on customer and transaction characteristics. In B2B sales, salespeople often offer different prices depending on customer demand characteristics. Using customer characteristics as a component of revenue management involves segmenting the market on variables that determine perceived value (i.e., willingness to pay and service requirements). For example, quantity discounts and free shipping are frequently used incentives to encourage large B2B customers to purchase in quantity to reduce sales, service, and delivery costs. Small, less profitable customers with fewer needs and little purchasing power pay full price and often times a fee for service and delivery. One firm in the electronic document management industry noted that prices may vary based on the degree to which the customer is perceived as "difficult" with which to work; that is, an aggressive customer who is highly demanding [33]. 
Common customer characteristics used by hotels and airlines include institution type, user status, service-level desired, and price consciousness. For example, certain types of customers, i.e., frequent purchasers, high volume purchasers, or purchasers with high budgets, typically receive different prices or benefits. Quantity sold is also a common price rate fence, as is the time lag between the sale and when the service or product delivery takes place. Effective rate fences divide customers according to the value they place on the product while preventing resale of the goods from low priced customers to higher priced customers [46]. Sales managers should develop appropriate price fences based on the consultative value received and requirements of customer segments with respect to the sales person, as well as their willingness to pay a premium for salesperson time. Again, customers must perceive that the sales force provides value through service behaviors, problem-solving capabilities, and information. The intent of the price fence is to shift demand for valued consultative or personal contact to those who are agreeable to compensating the firm for this service; to shift demand from price-sensitive customers from busy times to slow periods; to reward regular, reliable, and profitable customers; and to schedule the highest margin business during their time of preference to optimize perceptions of fairness. This strategy is discussed further under customer management.

In keeping with a customer orientation and in accordance with fairness principles, charging price premiums solely on the basis of limited supply and high demand, or charging price premiums to some groups but not to others during times of high demand, may cause customer resentment and be perceived as opportunistic and "unfair" [48]. Kahneman et al. [48] suggest that an approach of setting a "full" price during high-demand times (e.g., "rack rate" for hotel rooms) and then offering discounts during low demand times is viewed as more effective and fair than levying surcharges in the face of strong demand.

In determining who pays which price, managers must develop logical selection methods that hold value for customers without offending their sense of fairness (cf. Ref. [28]). As Kahneman et al. [48] discovered, customers go out of their way to punish a business that has acted unfairly. Consequently, firms must place concern for the customer at the forefront of revenue management strategies and manage customers using a customer orientation that addresses issues of perceived fairness. For instance, the price of capital equipment should include the extent to which the customer values not only the equipment but also the sales person's time invested in interaction and relaying knowledge. Thus, a concern for customers does not preclude the use of revenue management strategies; indeed, if a customer orientation is used properly, it can further enhance the firm's use of revenue management beyond the value of the product. For example, Kimes [49] discovered that hotel customers' perceptions of fairness of revenue management practices were enhanced if the customers realized the value of and were well informed about price fences and duration restrictions.

\subsection{Customer management}

\subsubsection{Customer-segmentation strategies}

Customer management uses market segmentation practices to gain insight into customer behavior, which in turn allows modifications to be made to the marketing mix to maximize company revenues while maintaining a given level of customer service. The customer segment categories identified by Shapiro et al. [36] (i.e., carriage trade, bargain basement, 
passive, and aggressive customers) appear to be good candidates on which to reference and augment the proposed segmentation tactics (see Table 4). The proposed customer categorization is determined by sensitivity to price, level of service demanded, performance expectations, and preferred communication style. The objective is to capture the customer's price and transaction references, and establish guidelines so that the revenue management strategy employed by the sales force will be perceived as fair. With the exception of Wal-Mart, Procter \& Gamble (P\&G) convinced retailers that using distributors rather than a direct sales contact from the P\&G sales force would best serve their needs. In effect customers ultimately determine the value placed on price vs. timely face-to-face service and their willingness to compensate for this service.

The carriage trade, as Shapiro et al. [36] note, represents both a high service cost and a strong revenue return to the firm. This group consists of decidedly price-insensitive customers who demand and gain value from high levels of salesperson time and service, but who are willing to financially compensate the firm for the elevated quantity and intensity of salesperson time desired. Oftentimes, these customers place costly one-time orders that require special-

Table 4

Customer-segmentation schema

\begin{tabular}{lll}
\hline Duration & Pricing & Variable \\
\cline { 2 - 3 } Controlled & Fixed & Quadrant 2 (passive customers) \\
& Quadrant 1 (bargain basement customers) & 1. Service sensitive \\
& 1. Service insensitive & 2. Price insensitive \\
& 2. Price sensitive & 3. Performance insensitive \\
3. Performance insensitive & 4. Amiable communication style & 5. Bundling purchase strategy \\
4ncontrolled & 4. Analytical communication style & Quadrant 4 (carriage trade customers) \\
& Quadrant 3 (aggressive customers) & 1. Service sensitive \\
& 1. Service sensitive & 2. Price insensitive \\
& 2. Price sensitive & 3. Performance sensitive \\
& 3. Performance sensitive & 4. Expressive communication style \\
& 4. Driver communication style & 5. Bundling purchase strategy \\
\hline
\end{tabular}

ized salesperson knowledge, customer training, and/or extensive follow-up service. Salespersons targeting buyers grouped in the "carriage trade" segment should be prepared to allocate disproportionate time as a means of building the desired relationship and justifying the fairness of the price. For example, the objective of an electronic document management firm's sales force is to present to the chief financial officer (CFO), as reaching this key decision-maker will be the most efficient use of sales time. The national sales manager reports that as long as the salesperson can effectively demonstrate that the most critical needs of the CFO can be reliably met, price is not an issue [33]. Similarly, the manager in the oil-well control and intervention business revealed that his company seeks to maintain amore "prestige" level of pricing and refuses to offer the discounts utilized by competing firms. His firm routinely does business with national oil companies, including Saudi Arabia and India, who are seeking the prestige of the firm name [45].

Those customers categorized as passive also yield strong revenue returns but are less costly to service than carriage trade customers. Passive customers are less demanding of salesperson time/service but, like carriage trade customers, are willing to pay high prices [36]. This customer segment values the specificity of the relationship and the flexibility of sales support, and is willing to forego immediate value for the good of the relationship and the future. The benefit of 
nurturing relationships with "passive customers" comes from continued loyalty, minimal price sensitivity over time, and an understanding of periodic service constraints [50]. Salespersons calling on passive customers should be prepared to spend extra time with these customers to develop the desired relationship by building a "rational" feeling of confidence that assuages the buyers' fears, so that the decision-making process can progress. The chairman and CEO of ARAMARK reports that prison systems follow the model of passive customers. Capturing the business of these bureaucratic systems is immensely time-consuming initially, but once the relationship is cemented, these customers are extremely loyal and not price conscious. The prison warden's goal is to ensure the inmates are satisfied and the warden dislikes having "strangers" around that can disrupt prison routines. Thus, once ARAMARK gains entree to a prison, the relationship remains firm as a result of their employee retention (no "strangers" lurking in the kitchen) and their superior food service, although there are competitors in place that would perform the service more cheaply [40].

The salesperson's contact time with carriage trade and passive customers should take precedence over other segments, since these two segments are receptive toward fairly compensating the firm for the salesperson's time and services. To reduce perceptions of unfairness and direct price comparisons with low cost customer segments, sales managers, for example, could bundle service and price to reflect the reciprocal long-term commitment to and value of the relationship from the "carriage trade" and "passive customer" perspective [38,51].

The bargain basement segment consists of consumers very sensitive to price, but relatively insensitive to service. This segment represents bargain hunters who seek the basic product at the lowest price, yet require minimal salesperson time [36]. These customers likely purchase regularly, are knowledgeable about the firm's product offerings, and are confident in their ability to purchase the right products to meet their needs without the assistance of salesperson product knowledge and communications. Salespersons calling on this group need not devote "prime" time to developing relationships, but must be prepared to provide quantities of data to support suggestions and claims. As a result, the sales call itself may not require much time, but preparation time may be greater. Because this customer segment does not require direct salesperson interaction, these customers need not be routinely serviced through personal sales calls. That is, products and salesperson time should be unbundled to reduce prices. In this case, these buyers should be tactfully guided to alternate selling vehicles (e.g., 800 telephone ordering systems, on-line catalogs or ordering capabilities, etc.) in exchange for lower prices or more time-efficient ordering techniques. As a result, salespersons can transfer valuable time to customer segments willing to compensate the firm for consuming salesperson time through personal attention and direct advice, while the firm effectively retains the business of a segment that does not desire salesperson interaction [52].

The final category is comprised of aggressive customers, the most difficult segment to cope with. This customer segment, aware of the service levels provided to passive and carriage trade segments and the price concessions offered to bargain basement segment, feels entitled to the lowest prices and the highest level of service, yet opportunistically declines to offset the extra costs incurred by the firm [13]. These customers often hold power in the industry and are cognizant of their importance to the selling firm's success. Aggressive customers frequently buy in large quantities or provide value to the firm by enhancing the firm's market reputation through positive association [36]. A high level of service is expected because of the stature or importance of the buyer to the firm. Salesperson knowledge is also valued 
but the buyer is unwilling to compensate the firm for salesperson time. For these customers, sales managers should develop tactics that reduce "prime" time sales contact, but not completely eliminate the amount of salesperson time and attention devoted to this segment. Aggressive customers should be encouraged to continue the relationship by creating value through alternative information and ordering systems. Creating an award structure specific to the value structure of "aggressive" customers could create perceptions of fairness without disrupting perceived fairness in other segments. For example, Web systems could be designed to speed information and order processes with this segment's demands in mind. Telemarketers, with direct links to the sales force, could be on-call at all times. While similar services could be available to all customer segments, for fairness purposes, these services will be targeted specifically to the price and service needs of the aggressive segment. Companies are already beginning to use these suggested tactics with their more aggressive customer segments [33]. For instance, WalMart, through aggressive negotiation, convinced P\&G to use a direct sales force when calling on the home office, despite the $P \& G$ rule to exclusively use distributors when calling on retailers. Winter [53] reported, however, that P\&G expected to obtain half of its orders from retailers such as Wal-Mart via P\&G's Web site.

In summary, the proposed classification schema reflects differences in customer value toward price- and timesensitive sales force services. Consequently, sales managers will have to carefully identify and define their customer segments in order to design revenue management strategies that result in optimal value for each market segment as well as optimal sales force performance.

\subsection{Outcomes}

The adoption of revenue management strategies for the sales force should have numerous positive consequences for the implementing firm. First, customer and price management will result in higher revenue per available sales hour and a focus on the highest margin clients. As the focus of sales efforts shift to the most profitable customer segments, and pricing is based on the willingness of these segments to compensate the firm for salesperson time, the overall sales revenues should increase. Further, since customers will be able to select their own price fences based on tradeoffs between the level of sales service desired, when they want it, and at a price they are willing to pay, customers' perceptions of fairness should enhance perceived sales effectiveness as well.

In conjunction with customer and price management, contact time management will result in an increase in sales calls per day. In addition, time management, as defined by the proposed revenue management strategies, will reduce the unproductive, nonselling time frequently faced by salespersons in exchange for sales calls desired by customers (cf. Refs. $[41,42])$. Equally important, and the actual focus of this paper, RevPASH will serve as a convenient, readily understood management tool for measuring the bottom-line efficiency and effectiveness of the sales force.

\section{A hypothetical example of sales force revenue management}

To illustrate practical applications of revenue management, the following scenario has been developed. This example (see Table 5), while hypothetical in nature, is based on data obtained from a large, multinational hotel chain. 
Consider the case of two corporate meeting services sales managers-Salespersons A and B-employed by a downtown hotel. These sales managers' responsibilities include obtaining bookings and servicing various organizations

\begin{tabular}{lrrr}
$\begin{array}{l}\text { Table } 5 \\
\text { Comparison of corporate services salesperson productivity }\end{array}$ & \\
\hline Contract & $\begin{array}{l}\text { Profit } \\
\text { (US\$) }\end{array}$ & Hours & $\begin{array}{l}\text { RevPASH } \\
\text { (US\$) }\end{array}$ \\
\hline Salesperson A & & & \\
World Cup 1 & 38,000 & 20 & 1900 \\
Press agency & 4000 & 10 & 400 \\
NBA team & 3000 & 5 & 600 \\
Regional association & 28,000 & 40 & 700 \\
Freight company & 3000 & 10 & 300 \\
Computer supply company & 10,000 & 10 & 1000 \\
Historical society & 2500 & 1 & 2500 \\
NBA team & 3500 & 10 & 350 \\
Software supplier & 7500 & 20 & 375 \\
World Cup 2 & 2000 & 5 & 400 \\
Total & 101,500 & 131 & 774.81 \\
& & & \\
Salesperson B & & & \\
Press agency & 1000 & 5 & 200 \\
National association & 150,000 & 300 & 500 \\
Total & 151,000 & 305 & 495.82 \\
\hline
\end{tabular}

that use hotel rooms, meeting space, and food and beverage. Sales managers are typically evaluated based on achieving a certain revenue volume. The goal for each salesperson is US\$100,000 in profit per month. Over the course of the last month, Salesperson A had 10 different contracts and brought in US\$101,500 in profit, while Salesperson B had one small and one very large contract and brought in US\$151,000. Both salespeople met the profit goal, but Salesperson B would be considered more productive because of the substantially higher revenue produced.

The evaluation changes when the sales manager includes the amount of time involved in securing, booking, and servicing each contract. While Salesperson B generated greater overall revenues, Salesperson A's time was used more efficiently. Salesperson A had a RevPASH of US\$775, while Salesperson B had a RevPASH of US\$496. Additionally, Salesperson A worked part-time during the month, averaging approximately 33 hours/week. Salesperson B, on the other hand, clocked approximately 76 hours/week (305 hours/ month) to capture the business. Had Salesperson A continued at the same rate per hour worked, she would have produced far more in revenues than Salesperson B. Salesperson B devoted nearly all her time to one account. While it is a valuable account, the organization may have been better served if she had sold in a more efficient manner as that may have also been the most effective manner in terms of revenue produced for the company. That is, if Salesperson B had produced on average what Salesperson A yielded (US\$774.81/hour), then Salesperson B would have produced US\$236,317.05 for the firm, rather than US\$151,000. An incremental gain of US\$85,375!

This finding points to the importance of sales force revenue management strategies. While Salesperson B is to be commended for "landing" a national association, previous research has noted that large accounts are not always the most profitable because of the time and discounts demanded by these clients $[36,40,41]$. Had revenue management strategies 
been employed by this hotel, Salesperson B would have focused on customer segments who were willing to pay higher prices to obtain her time and services, thus, insuring the firm of higher revenues and guaranteeing that Salesperson B's time was as effectively used as Salesperson A's. Those customers who were unwilling to pay for the additional service and knowledge provided by the salesperson could have been directed to utilize alternative methods of booking space. RevPASH can also help determine contract potential. For example, Salesperson A's contract with the regional association generated a high profit, but took 40 hours of work (RevPASH = US\$700) while the historical society was fairly small, but required only 1 hour of work (RevPASH = US\$2500) from Salesperson A. Better predicting the time involvement of salespeople for different types contracts, would allow salespeople to segment the contract market and prioritize their efforts with emphasis on the more profitable per sales hour contracts and incrementally add less profitable contracts pending time remaining.

The above examples illustrate the value of sales force time to the company in terms of immediate profits. Equally important is the allocation of sales force time to the relationship's future. Taking a customer orientation approach, salespeople should assess customer expectations and disposition toward sales force time. Pending the demands of the customer and profitability of accounts, sales managers should be better equipped to establish rules for pricing products and services that create price fences perceived as fair to all market segments. Time elasticity, in terms of duration and price from both the sales force and customer perspectives, should provide a better understanding of perceptions of fairness and solidify the future of the relationship (cf. Ref. [28]).

\section{Conclusions}

This study accomplishes several goals: (1) a broader perspective of revenue management is developed by extending the concept into the B2B sales force services arena, (2) the adoption of sales force revenue management is proposed as a solution for firms desiring improved sales efficiency metrics and increased sales revenues, and (3) a framework is developed for the implementation of sales force revenue management that can be readily used by practicing sales managers.

Presently, there is little evidence of sales managers implementing a strategic revenue management approach to improve and better measure sales force effectiveness. Yet, just as revenue management practices have revolutionized the manner in which airlines, hotels, restaurants, and other service industries maximize revenues for their perishable assets by strategically managing customer demand, the same dramatic transformations and benefits are available to forwardthinking sales managers who are willing to champion the cutting edge concept of sales force revenue management.

While some organizations inherently encourage salespeople to practice a few of the revenue management tactics described herein, there is little evidence of a strategic framework that can help managers coordinate these practices. The intent of this study is to explain revenue management from a B2B sales perspective and develop a roadmap for identifying revenue-management opportunities and selecting appropriate time management, customer management, and differential pricing approaches. Thus, a customer-oriented, unified framework for implementation is proposed. Furthermore, this approach should be easier to utilize and provide greater relevance to the practicing sales manager than 
the decision- calculus models previously advocated by academicians for use by industry.

Briefly, the framework begins with the characteristics required by organizations to successfully implement revenue management and most sales operations are demonstrated to meet the requirements demanded for effectual use of revenue management strategies. The framework next incorporates a customer orientation and then revenue management strategic levers, which can be undertaken by sales managers. That is, customer characteristics are included and specific tactics to manage time, customer segments, and price as a means of increasing satisfaction in conjunction with optimizing RevPASH are proposed. The framework then explores the potential outcomes of sales revenue management. A number of positive benefits are posited to accrue to firms embracing sales revenue management including higher RevPASH, higher revenue per sales call, increased sales call rate, reduced nonselling time, focus on highest margin clients, and enhanced customer perceptions of fairness.

\subsection{Managerial implications}

This study has several implications for managers. First, it emphasizes that achieving the full potential from revenue management lies in management's ability to market and manage the sales force as a revenue-producing asset and the salesperson as a unique service with limited and perishable resources. This step necessitates that managers alter their view of the sales force to that of a perishable asset providing a value-added service component that justifies price fences to reflect the value received and scarcity of salespeople's time.

Second, in conjunction with viewing sales force time as a perishable asset, methods of implementing revenue management (e.g., regulating contact time and incentives) that have not traditionally been a part of sales management strategies are proposed. Price fences based on the importance of particular customer segments and their need for the personal attention and consultative skills offered by the sales force should be developed. While the latter is not completely new as Shapiro et al. [36] proposed similar customer-segmentation tactics, the original customer classification schema was adapted and expounded upon for easier adoption and modification by sales managers. Further, while the focus of revenue management is on enhancing sales performance, the proposed methods emphasize the need for maintaining customer perceptions of fairness.

Third, revenue management results in a true measure of sales force efficiency: RevPASH. Moreover, it answers Krafft's [54] recent call for a measure that enhances both company profitability and salesperson utility. In today's competitive environment, firms are often unsure of the efficiency of their sales forces. Traditionally, firms have tried to use outcomebased measures of sales force performance, such as total sales dollars, or behavior-based measures, such as product knowledge, but both outcome- and behavior-based measures have their own unique set of advantages and disadvantages [12]. RevPASH, however, offers a new way of examining sales force performance. In contrast to previous measures, RevPASH focuses on sales force time as a perishable asset. As such, RevPASH is both an outcome- and behavior-based measure. The measure focuses on revenue produced for each available sales hour (outcome based), but also seeks to maximize profitability by dictating to whom, how, and when the sales force contacts customers (behavior based). RevPASH also provides a relatively easy metric for comparing salespeople and benchmarking against other firms. 
Fourth, the revenue management strategies suggested herein should also increase the profitability of the sales force by reducing selling costs and maximizing revenues. Not only will the sales force be able to increase the total number of customers serviced, but the focus of sales efforts will be on those customer segments who desire interaction with the salespeople. As such, the sales force will be more likely to gain commitment from these segments and these segments will be more willing to compensate the firm for salesperson time. Furthermore, attaching real value to sales force time may make the sales force more reluctant to resort to price discounting as a means of closing a sale if they recognize that they are reducing the value of their own time and thus, lowering their RevPASH score.

Fifth, the proposed sales force revenue management strategies also address the need for adopting dual selling models as currently advocated in the popular press and by consulting firms $[52,55]$. In essence, sales force revenue management focuses sales force time on the customer segments that most value consultative service, while encouraging those customers who prefer a transactional model of selling to purchase from the firm via on-line or telemarketing processes. As a result, each customer segment receives the desired level of service from the firm and the firm is able to direct its sales force to segments that will result in the greatest profitability to the organization and the greatest value for the customer. By uncovering diverse meanings of value and developing strategies that conform to effective price fences, sales managers can better regulate demand for sales force time and keep customers satisfied by applying the correct sales model to the appropriate customer segment. This approach also allows customers to self-select their own price/service classification to assure perceptions of fairness, while the sales operations safeguards sales force time by reducing the uncertainty of demand, reinforcing the rationality of price boundaries, and discouraging opportunistic behavior.

\section{References}

[1] Smith BC, Leimkuler JF, Darrow RM. Yield management at American Airlines. Interfaces 1992;22(1):8-31.

[2] Hanks RD, Cross RG, Noland RP. Discounting in the hotel industry: a new approach. Cornell Hotel Restaur Adm Q 1992;33(May):40-5.

[3] Kimes SE. Revenue management on the links: applying yield management to the golf-course industry. Cornell Hotel Restaur Adm Q 2000; 41(February):120-7.

[4] Kimes SE, Chase RB, Choi S, Lee P, Ngonzi E. Restaurant revenue management: applying yield management to the restaurant industry. Cornell Hotel Restaur Adm Q 1998;39(June):32-9.

[5] Kimes SE, Young F. The Shuttle by United. Interfaces 1997;27(3): 1-13.

[6] Sexton RJ, Johnson NB, Konakayama A. Consumer response to continuous-display electricity-monitors in a time of use pricing experiment. J Consum Res 1987;14(June):55 -62.

[7] Behrman DN, Perreault Jr WD. Measuring the performance of industrial salespersons. J Bus Res 1982;10(September):355-70.

[8] Brown AA, Hulswit FT, Kettelle JD. A study of sales operations. Oper Res Q 1956;4(June):296-308. 
[9] Cravens DW, Ingram TN, LaForge RW, Young CE. Behavior- based and outcome-based salesforce control systems. J Mark 1993; 54(October):47-59.

[10] Lodish LM. CALLPLAN: an interactive salesman's call planning system. Manage Sci 1971;18, Pt 2(December):25-40.

[11] Oliver RL, Anderson E. An empirical test of the consequences of behavior- and outcome-based sales control systems. J Mark 1994;58 (October):53 -67.

[12] Anderson E, Oliver RL. Perspectives on behavior-based versus outcome-based salesforce control systems. J Mark 1987;51(October): 76-88.

[13] Williamson OE. The economic institutions of capitalism. New York: Free Press; 1985.

[14] Kimes SE. Yield management: a tool for capacity-constrained service firms. J Oper Manag 1989;8(4):348-63.

[15] Weatherford LR, Bodily SE. A taxonomy and research overview of perishable-asset revenue management: yield management, overbooking, and pricing. Oper Res 1992;40(September/October):831-43.

[16] Marketing Science Institute Top Priority 2000-2002.

[17] Bush AJ, Anderson RE, Hair Jr JF. Professional sales management. 3rd ed. New York: McGraw-Hill; 1999.

[18] Jackson DW, Schlacter JL, Wolfe WG. Examining the bases utilized for evaluating salespeople's performance. J Pers Sell Sales Manage 1995;15(Fall):57-65.

[19] Lodish LM. Vaguely right approach to sales force allocations. Harvard Bus Rev 1974;52(January/February):119-24.

[20] Montgomery DB, Silk AJ, Zaragoza CE. A multiple-product sales force allocation model. Manage Sci 1971;18, Pt 2(December):3-24.

[21] Fudge WK, Lodish LM. Evaluation of the effectiveness of a model based salesman's planning system by field experimentation. Interfaces 1977;8(November):97-106.

[22] Lodish LM. Sales territory alignment to maximize profits. J Mark Res 1975;12(February):30-6.

[23] Lodish LM. Assigning salesmen to accounts to maximize profit. J Mark Res 1976;13(November):440-4.

[24] Lodish LM, Curtis E, Ness M, Simpson MK. Sales force sizing and deployment using a decision calculus model at Syntex. Interfaces 1988;18(January/February):5-20.

[25] Parasuraman A, Day RL. A management oriented model for allocating sales effort. J Mark Res 1977;14(February):2233.

[26] LaForge RW, Cravens DW. Empirical and judgment-based sales-force decision models: a comparative analysis. Decis Sci 1985;16(Spring): 177-95.

[27] Webster Jr FE. The changing role of marketing in the corporation. J Mark 1992;58(October):1-17.

[28] Dorsch MJ, Carlson L, Raymond MA, Ranson R. Customer equity management and strategic choices for sales managers. 
J Pers Sell Sales Manage 2001;2(Spring):157-66.

[29] Kimes SE. The basics of yield management. Cornell Hotel Restaur Adm Q 1989;30(November):14-9.

[30] Kimes SE, Chase RB. The strategic levers of yield management. J Serv Res 1998;1(November):156-66.

[31] Bollapradaga S, Cheng H, Phillips M, Garbiras M, Scholes M, Gibbs T, et al. NBC's optimization systems increase revenues and productivity. Interfaces 2002;32(1):47-60.

[32] Seconmandi N, Abbott K, Atan T, Boyd EA. From revenue management concepts to software systems. Interfaces 2002;32(2):1-11.

[33] Burton JE. Personal interview with national sales manager of ImageMax, September 12, 2002.

[34] Cross RG. Revenue management. New York: Broadway Books; 1997.

[35] Cross RG. Launching the revenue rocket: how revenue management can work for your business. Cornell Hotel Restaur Adm Q 1997;38 (April):32-43.

[36] Shapiro BP, Rangan VK, Moriarty RT, Ross EB. Manage customers for profits (not just sales). Harvard Bus Rev 1987;65(September- October):101-8.

[37] Greco S. Are your prices right? Inc. 1997;(Januaiy):88-89.

[38] Gassenheimer JB, Houston FS, Davis JC. The role of economic value, social value, and perceptions of fairness in interorganizational relationship retention decision. J Acad Mark Sci 1998;26(Fall):322-37.

[39] Karmarkar US. Integrative research in marketing and operations management. J Mark Res 1996;33(May):125-33.

[40] Neubauer J. Personal interview with the chairman and CEO of ARAMARK, September 19, 2002.

[41] Reinartz WJ, Kumar V. On the profitability of long-life customers in a noncontractual setting: an empirical investigation and implications for marketing. J Mark 2000;64(October):17-35.

[42] Reinartz WJ, Kumar V. The mismanagement of customer loyalty. Harvard Bus Rev. 2000;(July):4-12.

[43] Churchill Jr GA, Ford NM, Walker Jr OC, Johnston MW, Tanner Jr JF. Sales force management. 6th ed. New York: McGraw-Hill; 1999.

[44] Weitz BA, Castleberry SB, Tanner JF. Selling: building partnerships. 4th ed. Chicago: Irwin; 2001.

[45] Siguaw TR. Personal interview with project manager, senior engineer of Boots 'n Coots, September 12, 2002.

[46] Hopkins T. How to master the art of selling. New York: Warner Books; 1994.

[47] Dolan RJ, Simon H. Power pricing. New York: Free Press; 1996.

[48] Kahneman D, Knetsch JL, Thaler R. Fairness as a constraint on profit seeking: entitlements in the market. Am Econ Rev 1986;76(4): 728-41. 
[49] Kimes SE. Perceived fairness of yield management. Cornell Hotel Restaur Adm Q 1994;35(February):22-9.

[50] Bowen JT, Shoemaker S. Loyalty: a strategic commitment. Cornell Hotel Restaur Adm Q 1998;39(February):12-25.

[51] Dwyer FR, Schurr PH, Oh S. Developing buyer-seller relationships. J Mark 1987;51(April):11-27.

[52] Rackham N, DeVincentis JR. Rethinking the sales force: redefining selling to create and capture customer value. New York: McGraw- Hill; 1999.

[53] Winter G. Procter sets ambitious goals. N Y Times 2000;(October 11): C-4.

[54] Krafft M. An empirical investigation of the antecedents of sales force control systems. J Mark 1999;63(July):120-34.

[55] Randery T. Restructuring the sales force: what this means for our customers. Presentation at the American Marketing Association Sales Consortium (July), Orlando (FL); 1999. 